\title{
ROL BELİRSIZZLIIĞİ VE SANAL KAYTARMA: GÖRGÜL BİR ARAŞTIRMA
}

$* * * *$

\section{ROLE AMBIGUITY AND CYBERSLACKING: AN EMPIRICAL STUDY}

\author{
Dr. Öğr. Üyesi Utku GÜĞERÇìN \\ Adana Alparslan Türkeş Bilim ve Teknoloji Üniversitesi \\ İşletme Fakültesi \\ Yönetim Bilișim Sistemleri Bölümü \\ ugugercin@adanabtu.edu.tr \\ ORCID: 0000-0002-7667-6256
}

Emel Berkem SIĞIRCIKOĞLU

Adana Alparslan Türkeş Bilim ve Teknoloji Üniversitesi Sosyal Bilimler Enstitüsü Yönetim ve Organizasyon ABD Yüksek Lisans Öğrencisi emelberkem@gmail.com ORCID: 0000-0002-0527-142X

\section{Öz}

Çalışanların görev, yetki ve sorumluluklarının net olarak tanımlanmamıs olması ve/veya görevleri ile ilgili olarak kendilerinden beklenilen davranışların çalışanlara açıķ̧a bildirilmemesi rol belirsizliği olarak adlandirlmaktadır. Rol Teorisi'nden hareketle; rol belirsizliği yaşayan çalışanların, maruz kaldıkları stresten dolayl üretkenlik ve performans karşıtı davranışlara yönelebilecekleri öngörülmektedir. Rol belirsizliğine verilen tepkiler farklılaşmakla birlikte, işyerlerinde artan internet kullanımı neticesinde çalışanlar, rol belirsizliğine tepki olarak sanal kaytarma davranışlarına yönelebilirler. Bu bağlamda bu araştırmanın amacı rol belirsizliğinin, 'dijital çă̆ın kahve molası' şeklinde tanımlanabilecek sanal kaytarma davranışlarını nasıl etkilediğini ortaya koymaktır. Türkiye'deki işletmelerde rol belirsizliğinin yüksek seviyede olmasina ve işyerlerinde internet erişsiminin yaygınlaşmasına rağmen, rol belirsizliği ve sanal kaytarma iliş̧kisini ele alan herhangi bir çallş̧maya rastlanmamış olmasl, araştırmanın önemini ortaya koymaktadır. Araştırma; özel sektör çalı̧̧anları üzerinde, anket yöntemi kullanılarak gerçekleştirilmiştir. Analiz sonuçlarına göre çalışanların yaşadıkları rol belirsizliği, sanal kaytarma davranışlarını artırmaktadır. Bu doğrultuda, çalışanlara daha az rol belirsizliği yaşayacakları bir çalışma ortamı sunularak, mesai saatleri içerisinde kişisel amaçlı internet kullanımının azaltılmaya çalışılması önerilmektedir.

Anahtar Kelimeler: rol belirsizliği, sanal kaytarma, siber kaytarma, siber aylaklık, işyerinde iş dışl internet kullanımı.

\begin{abstract}
The lack of clear definitions regarding the employees' duties, authorities, and responsibilities and/or the absence of explicit disclosure of the expected behaviors in relation to the duties of the employees is called role ambiguity. According to the Role Theory; employees, who experience role ambiguity, may act against productivity and performance due to the stress they are exposed to. Although reactions to role ambiguity differ, as a result of the increased internet use in the workplaces, employees are more prone to engage in cyberslacking behaviors in response to role ambiguity. In this context, the aim of this study is to determine how role ambiguity affects cyberslacking behaviors, which can be defined as 'the coffee break of the modern age'. Despite the high level of role ambiguity and increasing use of the internet in Turkish businesses, the absence of any study analyzing the relationship between role ambiguity and cyberslacking reflects the significance of the study. Data is gathered by survey method and the sample was consisted of private sector employees. Results of the analysis revealed that role ambiguity has a significant positive effect on cyberslacking activities. In this regard, in order to lessen the usage of the internet for personal purposes during working hours, it is recommended that employees should have a working environment with less role ambiguity.
\end{abstract}

Keywords: role ambiguity, cyberslacking, cyberloafing, cyber-leisure, non-work related internet use at work. 


\section{GÍRIŞ}

Bilgi ve iletişim teknolojilerindeki gelişmeler, günlük hayat için pek çok kolaylık sağlarken iş hayatı için de çeşitli avantajlar sağlamıştır. Özellikle, bilgi ve iletişim teknolojilerinin bileşenlerinden biri olan ve artık günümüzün vazgeçilmezi haline gelen internet, bilgiye daha kısa sürede ve daha kolay ulaşma imkanı doğurmuştur. Ayrıca internet son dönemlerde, Endüstri 4.0'ın etkisiyle nesnelerin interneti, bulut bilişim, artırılmış gerçeklik ile köklü değişimler yaratmaktadır (Eldem, 2017). Hatta internet kullanımı 20. yüzyıl itibariyle işletme giderlerinin azaltılması, online satış, zaman tasarrufu gibi olanaklar sunarken (Anandarajan vd., 2000), günümüzde marka ve halkla ilişkiler yönetimi, kişiselleştirilmiş ürün ya da hizmet sunumu, hatta tüketicilerle ilgili veri temin etme aracı olarak kullanılmaktadır. Fakat tüm bu beraberinde getirdiği olanakların yanı sıra internetin bilinçsiz kullanımı gün geçtikçe artan bir trend içerisinde seyretmektedir. Dolayısıyla internet kullanımı işletmeler için avantaj yanında tehdit niteliği de taşımakta (Wheatherbee, 2010) ve işletmeleri ciddi maliyetlerle karşı karşıya bırakmaktadır (Örücü ve Yıldız, 2014:99). İşyerlerinde internet kullanımından kaynaklanan problemlerden biri de "dijital çağın kahve molası" olarak nitelendirilebilecek sanal kaytarmadır.

Sanal kaytarma, çalışanların iş saatleri içerisinde işletme faaliyetlerinden bağımsız olarak, kişisel amaçlar doğrultusunda web uygulamalarını kullanmaları olarak tanımlanabilir (Lim, 2002:675). Başka bir deyişle sanal kaytarma, mesai saatleri içerisinde iş ile ilgili olmayan internet kullanımını ifade etmektedir. Sanal kaytarma literatürde; sanal (siber) sapkınlık ya da işte kişisel internet kullanımı (Vitak vd., 2011:1751) olarak tanımlandığı gibi Türkçe yazında siber kaytarma, siber aylaklık, sanal tembellik olarak da anılmaktadır. Mesai saatlerinde sosyal medyada vakit geçirmek, online alışveriş̧ yapmak, bahis sitelerine girmek gibi eylemler sanal kaytarma davranışları kapsamındadır. Sanal kaytarma ile ilgili olarak gerçekleştirilen bir araştırmanın sonucuna göre, internet üzerinden alışveriş, borsa, açık artırma ve kumar sitelerinin kullanımı $\% 60$ oranında mesai saatlerinde gerçekleşmektedir (Sharma ve Gupta, 2004:76). Konuyla ilgili yurtdışında yapılan piyasa araştırmalarının sonuçlarına göre çalışanların internette geçirdikleri sürenin yarıdan fazlası işle ilgili olmayan konuları kapsamakta, erkek çalışanların \%4'ü mesai saatlerinde günde yaklaşık 1-2 saat kumar oynamakta, kadınların ise \%49'u tatil sezonunda mesai saatleri içerisinde online alışveriş yapmaktadırlar (MySammy, 2013). Ayrıca farklı iki araştırma neticesinde, çalışanların günlük 2,5 saatten haftalık 3 saate kadar kişisel amaçlı internet kullandıkları ortaya konulmuştur (Greenfield ve Davis, 2002; Mills vd., 2001). Liberman vd. (2011)'ne göre sanal kaytarma hem örgüte hem de örgüt çalışanlarına zarar vermekte, söz konusu zararlar internet hatlarında meydana gelen yoğunluk, azalan verimlilik sonucu gerçekleşen milyarlarca dolarlık maddi kayıplar, şirket gizliliğinin ihlali, çalışanların işten çıkarılması ve hatta yasal yaptırımlar şeklinde gerçekleşebilir. Bu görüşü destekler nitelikte, internetin kişisel amaçlarla kullanılmasının işletmelere toplam maliyetinin yıllık 54 milyar dolar olduğu tespit edilmiştir (Young, 2001:7).

Sanal kaytarma ile ilgili yapılmış olan çalışmalarda çoğunlukla; sanal kaytarma davranışlarının sıklığı (Didden vd., 2009), sanal kaytarma davranışlarının örgütler ve örgüt çalışanları üzerindeki olumsuz etkileri (Wheatherbee, 2010), ziyaret edilen internet sitelerinin türü (Lim vd., 2002; Lim vd., 2005) ve işverenlerin sanal kaytarma davranışlarına yanıt olarak uyguladıkları internet kullanım politikaları, izleme yazılımları ve filtreleri gibi konular incelenmiştir (Ugrin vd., 2008). Söz konusu çalışmaların yanı sıra sanal kaytarmanın öncüllerinin ve ardıllarının da araştırma konusu olduğu görülmüş̧ür. Özellikle uluslararası yazında sanal kaytarmanın iş tatmini (Mahatanankoon, 2006; Messarra vd., 2011), örgütsel adalet (Restubog vd., 2011), rol belirsizliği (Henle ve Blanchard, 2008; Sawitri ve Cahyadin, 2012), örgütsel bağl1lık (Niaei vd., 2014; Shamsudin vd., 2012) gibi öncüllerine odaklanıldığı görülmektedir. Ulusal yazında ise her ne kadar örgütsel adalet (Öğ̈̈t vd., 2013; Yıldız vd., 2015), iş tatmini (Çavuşoğlu ve Palamutçuoğlu, 2017; Çivilidağ, 2017), örgütsel bağl1lık (Candan ve İnce, 2016; Güngör, 2016) gibi öncüllerin sanal kaytarma ile olan ilişkisi üzerinde çalışılmış olsa da ülkemizde işgörenlerin sıklıkla maruz kaldıkları rol belirsizliğinin (Polatçı ve Boyraz, 2010) sanal kaytarma ile ilişkini doğrudan konu alan herhangi bir çalışmaya rastlanılmamıştır.

Örgütsel davranışı etkileyen önemli stres kaynakları arasında yer alan rol belirsizliği; çalışanların görev, yetki ve sorumluluklarının net olarak tanımlanmamış olması ve/veya görevleri ile ilgili olarak kendilerinden beklenilen davranışların çalışanlara açıkça bildirilmemesi şeklinde 
tanımlanabilir (Kahn vd., 1964). Rol Teorisi'ne göre (Kahn vd., 1964), çalışanların birbiri ile çelişkili ve net olarak açıklanmayan iş rolleri ile karşılaşmaları, yani rol belirsizliği yaşamaları durumunda, görevleri arasında denge kurmaları zorlaşabilmekte, bu durum da strese maruz kalmalarına sebep olmakta ve performansları olumsuz yönde etkilenmektedir (Rizzo vd., 1970). Bu çerçevede rol belirsizliği, çeşitli örgütlerde ve mesleklerde yaygın olan bir stres kaynăg 1 olarak kabul edilmektedir (Henle ve Blanchard, 2008). Oysa çalışanların uyumu ve başarısı, rol ve işlevlerinin net bir şekilde tanımlanmış olmasına, işyerindeki her çalışanın kendi rol ve işlevlerini en üst düzeyde yerine getirebilme yeterliliğine ve olanağına sahip olmasına bağlıdır (Aslan, 2004:602). Özellikle Türkiye'deki işletmelerde görev tanımlarının açık biçimde belirlenmemiş olması sebebiyle (Aslan, 2004; Korkut vd., 1999; Koşar vd., 2013) ülkemiz işletmelerinde rol belirsizliğinin yüksek seviyede olduğu düşünülmektedir. Bunun sonucunda çalışanlar, yaşadıkları rol belirsizliğinin yol açtığı stres ve performans yetersizliği ile başa çıkma mekanizması olarak sanal kaytarma davranışına yönelebilmektedirler (Folkman ve Lazarus, 1988; Henle ve Blanchard, 2008; Sawitri, 2012). Bu bağlamda rol belirsizliğinin sanal kaytarma ile ilişkisinin incelenmesi önem taşımaktadır. Bu konuya odaklanan Sawitri (2012:324) çalışanların, interneti kullanma bilgi ve becerilerine bakılmaksızın rol belirsizliğine maruz kalmaları durumunda daha fazla sanal kaytarma davranışına yöneldiklerini tespit etmiş̧ir. Henle ve Blanchard (2008) tarafından yapılan bir başka çalışmanın neticesinde ise çalışanların, rol belirsizliğinin olumsuz etkileri ile başa çıkmak için sanal kaytarma davranışlarını savunma mekanizması olarak kullanabilecekleri ortaya konulmuştur. Ancak Türkiye'deki yüksek düzeydeki rol belirsizliğine rağmen, ulusal yazında rol belirsizliği ve sanal kaytarma ilişkini doğrudan konu alan herhangi bir çalışmaya rastlanılmamıştır. Bu noktadan hareketle bu çalışmanın temel amacı, ülkemizde sıklıkla karşılaşılan rol belirsizliğinin sanal kaytarma davranışları üzerindeki etkisini tespit etmektir. Alanyazındaki mevcut bulgulardan hareketle çalışmanın hipotezi ' $\mathrm{H}_{1}$ : Çalışanların maruz kaldıkları rol belirsizliği, sanal kaytarma davranışları üzerinde pozitif yönde etkilidir.' şeklinde oluşturulmuştur. Çalışma kapsamında ayrıca çalışanların sanal kaytarma davranışlarına ne kadar zaman ayırdıklarının ve sanal kaytarma için hangi araçları kullandıklarının da tespit edilmesi amaçlanmaktadır.

\section{METODOLOJI}

\subsection{Veri Toplama Süreci ve Örneklem}

Araştırmada kullanılan veriler hem elden hem de online anket yöntemi ile kolayda örnekleme yoluyla elde edilmiştir. Araştırmanın evreni, Türkiye'deki işletmelerde çalışı mesai saatleri içerisinde internete bağlanma imkanına sahip işgörenlerden oluşmaktadır. Araştırmanın örneklemi ise Adana ve Mersin illerinde kurulu, özel sektörde faaliyet gösteren hizmet işletmeleri çalışanlarından oluşmaktadır. Evrenin büyüklüğünün net olarak bilinmediği durumlarda, anket formundaki ifade sayısının 10 katı kadar katılımcıya ulaşılması, kabul gören bir yaklaşımdır (Costello ve Osborne, 2005:4). Ancak bu oranın 5'in altına inmemesi önerilmektedir (Hair, 2010:175). Söz konusu yeterlilikleri sağlamak amacıyla bu çalışma kapsamında, kolayda örnekleme yöntemi ile 250 anket formu dağıtılmıştır. 233 adet geri dönen anket formunun 37'si eksik yanıtlandığı için analiz dış1 bırakılmış ve nihai olarak 196 adet anket analiz edilmiştir. Anket formundaki toplam ifade sayısının 20 olduğu göz önüne alınarak, analize dahil edilen anket formu sayısının asgari yeterliliği sağladığı ve tavsiye edilen sayıya yakın olduğu görülmüştür.

Anket formunda rol belirsizliği değişkeninin ölçümü için Rizzo vd. (1970) tarafından geliştirilen 'Rol Çatışması ve Rol Belirsizliği Ölçeği'nden faydalanılmıştır. Bu ölçeğin ülkemizdeki geçerlik ve güvenirlik çalışması Erigüç (1994) tarafindan gerçekleştirilmiştir. Ölçekte, rol belirsizliği boyutunu ölçen 6 adet ifade bulunmaktadır. "İ̧yerinde ne kadar yetkiye sahip olduğumu biliyorum." ifadesi, bu ölçekteki ifadelere örnek olarak verilebilir. Sanal kaytarma değişkeninin ölçümü için ise Örücü ve Yıldız (2014) tarafından farklı ölçeklerdeki (Blanchard ve Henle, 2008; Lim, 2002; Özkalp vd., 2012) ifadelerin bir araya getirilmesi ile oluşturulan ve 14 ifadeden oluşan sanal kaytarma ölçeği kullanılmıştır. Ölçeklerdeki tüm ifadeler beşli likert tipinde olup rol belirsizliği ölçeğindeki ifadelere katılım düzeyi ' $1=$ Hiç Katılmıyorum'dan '5=Tamamen Katılıyorum'a doğru; Sanal Kaytarma 
Ölçeği'ndeki ifadeler ise '1=Hiçbir Zaman'dan '5=Her Zaman'a doğru sıralanmıştır. Ölçeklerdeki ifade sayıları ile birlikte, bu çalışma kapsamında gerçekleştirilen güvenirlik analizi sonucunda elde edilen değerler, Tablo 1'de yer almaktadır.

Tablo 1: Araştırmada Kullanılan Ölçeklere İlişkin Bilgiler

\begin{tabular}{lcc}
\hline Ölçek & İfade Sayısı & Cronbach's Alpha \\
\hline Rol Belirsizliği Ölçeği & 6 & .88 \\
Sanal Kaytarma Ölçeği & 14 & .84 \\
\hline
\end{tabular}

Anket formunda ayrıca katılımcıların demografik özelliklerini belirlemek üzere oluşturulan kişisel form yanında, daha önce Demir vd. (2017)'nin çalışmasında yer alan, çalışanların sanal kaytarma davranışlarına ne kadar zaman ayırdıklarını ve sanal kaytarma için hangi araçları kullandıklarını tespit etmeyi amaçlayan sorular da bulunmaktadır. Katılımcıların samimi cevap verebilmeleri için bu sorular anket formunda 'sanal kaytarma davranışına ayrılan zaman' ve 'sanal kaytarma için kullanılan araçlar' şeklinde değil, 'iş dışı internet kullanımına ayrılan zaman' ve 'iş dışı internet erişimi için kullanılan araçlar' şeklinde sorulmuştur.

\subsection{Bulgular}

\subsubsection{Verilerin Analize Uygunluğu ve Katılımcıların Demografik Özelliklerine Yönelik Bulgular}

Verilerin analizi aşamasında öncelikle eksik değerlere (missing values) odaklanılmıştır. Toplam 233 adet anket formundan 37'sinde, demografik özellikler ve iş dışı internet kullanım alışkanlıkları ile ilgili sorular eksik yanıtlanmıştır. Dolayısıyla ilgili formlar analiz dışı bırakılmıştır. Ayrıca rol belirsizliği düzeyini ve sanal kaytarma sıklığını ölçen ifadelerden de bazılarının yanıtsız bırakıldığı görülmüştür. Yanıtsız bırakılan bu ifadeler, anket formundaki ifadelerin toplamının \%1'inin altındadır. Oranın oldukça düşük olması nedeniyle analizler aleyhine bir durum bulunmamaktadır. Eksik değerlerin analize uygun hale getirilmesi amacı ile bu değerlere bulundukları grubun ortalamaları yazılmış (Acuna ve Rodriguez, 2004:639), nihai olarak 196 adet anket analiz edilmiştir.

Normal dağılım varsayımının kontrolü için Kolmogrov-Smirnov ve Shapiro-Wilks testleri uygulanmış, ayrıca ölçek ifadelerinin basıklık ve çarpıklık değerleri incelenmiştir. Test sonuçları verilerin normal dağılımdan düşük düzeyde sapma gösterdiğini ortaya koymuş, dağılımın şeklinden normallik varsayımının ihlal edilmediği, basıklık ve çarpıklık değerlerinin de \pm 2 sınırı içerisinde olduğu görülmüştür. Dolayısıyla verilerin dağılımının analizler için engel teşkil etmediği anlaşılmıştır.

Araştırma kapsamındaki özel sektör çalışanlarının sosyo-demografik özelliklerine yönelik bulgulara göre, katılımcıların \%50.5'i erkek ( $\mathrm{n}=99)$, \%60.7'si bekar $(\mathrm{n}=119), \% 51$ 'i ise 30 yaş ve altındadır (n=100). Katılımcıların \%52.1'i lisans veya lisansüstü (yüksek lisans veya doktora) eğitim derecesine sahip olup $(\mathrm{n}=102), \% 57.7$ 'sinin toplam iş tecrübesi 5 yıldan fazladır $(\mathrm{n}=113)$. Katılımcıların demografik özelliklerine ilişkin detaylar, Tablo 2'de yer almaktadır.

Tablo 2: Katılımcıların Demografik Özellikleri

\begin{tabular}{lcclcc}
\hline Özellikler & $\mathrm{n}$ & $\%$ & Özellikler & $\mathrm{n}$ & $\%$ \\
\hline Cinsiyet & & & Eğitim Durumu & & \\
Erkek & 99 & 50.5 & Lise ve altı & 62 & 31.6 \\
Kadın & 97 & 49.5 & Ön lisans & 32 & 16.3 \\
Medeni Durum & & & Lisans & 88 & 44.9 \\
Evli & 77 & 39.3 & Lisansüstü & 14 & 7.2 \\
Bekar & 119 & 60.7 & Toplam iş tecrübesi (yll) & & \\
Yaş & & & 5 veya daha az & 83 & 42.3 \\
30 ve altı & 100 & 51.0 & 6-10 arası & 54 & 27.6 \\
\hline
\end{tabular}




\begin{tabular}{llllll}
\hline $31-40$ & 68 & 34.7 & $11-20$ aras1 & 44 & 22.4 \\
41 ve üstü & 28 & 14.3 & 21 ve üstü & 15 & 7.7 \\
\hline
\end{tabular}

\subsubsection{Katılımcıların Sanal Kaytarma Süreleri ve Kullandıkları Araçlar}

Demir vd. (2017)'nin sanal kaytarma konusunu ele alan görgül çalışmalarında kullanmış oldukları tanımlayıcı istatistikler bu çalışma kapsamında da kullanılmıştır. Çalışanlara mesai saatleri içerisinde iş dışı internet kullanımı amacıyla ne kadar zaman harcadıkları sorulduğunda; \%61.2' sinin 1 saatten az $(n=120), \% 26.5^{\prime}$ inin 1-3 saat arası $(n=52), \% 3.6$ ' $\sin 1 n$ 3-5 saat aras $(n=7)$, ve \%8.7'sinin 5 saat ve üzeri $(\mathrm{n}=17)$ sanal kaytarma yaptığı anlaşılmıştır.

Her ne kadar literatürde sanal kaytarma davranışlarının işyeri bilgisayarları aracıllı̆̆yla gerçekleştiği varsayılmış ve sanal kaytarma bu şekilde kavramsallaştırılmış olsa da cep telefonu ve tablet gibi cihazların yaygınlaşması, sanal kaytarmanın işyeri bilgisayarı dışındaki araçlarla gerçekleşebileceğine işaret etmektedir. Bu noktadan hareketle araştırma kapsamında çalışanlara, işyerlerinde mesai saatleri içerisinde kişisel amaçlarla internete erişmek için hangi araçları kullandıkları da sorulmuştur. Katılımcıların \%8.7'sinin sadece işyeri bilgisayarından $(\mathrm{n}=17), \% 57.1$ 'inin sadece şahsi araçlarından (tablet, cep telefonu gibi) ( $\mathrm{n}=112), \% 34.2$ 'sinin $(\mathrm{n}=67)$ ise hem işyeri bilgisayarından hem de şahsi araçlarıyla sanal kaytarma yaptıkları belirlenmiştir. Dolayısıyla bu araştırmadaki örneklem içerisinde sanal kaytarma davranışlarını 'tamamen şahsi araçlarını kullanarak ya da işyeri bilgisayarı ile birlikte şahsi araçlarını da kullanarak' gerçekleştirenlerin toplam oranı \%91.3’tür.

\subsubsection{Sanal Kaytarma ve Rol Belirsizliğine Yönelik Bulgular}

Araştırmaya katılan özel sektör çalışanlarının sanal kaytarma davranışları ortalamalarının $\bar{x}=2.95$

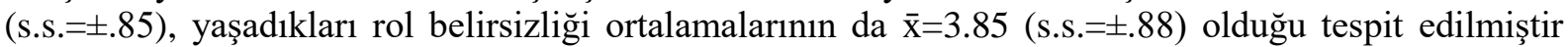
(Tablo 3). Yapılan korelasyon analizi sonucuna göre, bu iki değişken arasında istatistiki olarak anlamlı ve pozitif yönlü bir ilişki bulunmaktadır $(r=.35, \mathrm{p}<.01)$. Korelasyon katsayısı, ilişkinin kuvvetinin orta düzeyde olduğunu göstermiştir (Urdan, 2011).

Tablo 3: Tanımlayıcı İstatistikler ve Değişkenler Arası Korelasyon Katsayıları

\begin{tabular}{lcccc}
\hline Değişkenler & Ortalama & Standart Sapma & S.K. & R.B. \\
\hline Sanal Kaytarma (S.K.) & 2.95 & .85 & 1 & \\
Rol Belirsizliği (R.B.) & 3.85 & .88 & $.350^{* *}$ & 1 \\
\hline \multicolumn{1}{c}{$<0,01$} & & &
\end{tabular}

Çalışanların iş yerlerinde maruz kaldıkları rol belirsizliğinin, sanal kaytarma davranışları üzerindeki etkisini belirlemek amacı ile doğrusal regresyon analizi uygulanmıştır. Analiz sürecinde öncelikle değişkenler arasında otokorelasyonun olup olmadığ1 incelenmiştir. Uygulanan regresyon modelinde Durbin Watson katsayısının 2,5'un altında olması (Durbin ve Watson, 1951), değişkenler arasında otokorelasyonun olmadığını göstermektedir. Tablo 4'te görülen basit doğrusal regresyon analizi sonucunda oluşturulan araştırma modeli anlamlı bulunmuş $(\mathrm{F}=26.995 ; \mathrm{p}<.001)$, rol belirsizliğinin sanal kaytarma davranışları üzerinde pozitif yönde etkili olduğu $(\beta=.34, p<.001)$ görülmüştür. 
Tablo 4: Basit Doğrusal Regresyon Sonuçları

\begin{tabular}{|c|c|c|c|c|c|}
\hline Bağımsız Değişken & B & Standart Hata & $\beta$ & $\mathbf{t}$ & $\mathbf{P}$ \\
\hline Sabit & 1.65 & .26 & & 6.41 & .000 \\
\hline Rol Belirsizliği & .34 & .07 & .35 & 5.20 & .000 \\
\hline
\end{tabular}

Araştırma modelinin $\mathrm{R}^{2}$ değeri .12'dir (düzeltilmiş $\mathrm{R}^{2}=.12$ ). Buna göre çalışanların maruz kaldıkları rol belirsizliği, sergiledikleri sanal kaytarma davranışlarındaki varyansın \%12'lik kısmını açıklamaktadır. Geriye kalan varyans, modele ilave edilecek farklı değişkenler tarafindan açıklanabilir. Özetle, çalışanların yaşadıkları rol belirsizliğinin sanal kaytarma eylemleri üzerinde pozitif yönde ve istatistiki olarak anlamlı düzeyde etkili olduğu bulgulanmış $(\beta=.34, p<.001)$, çalışmanın hipotezi desteklenmiştir.

\section{TARTIŞMA VE SONUÇ}

Bu çalışmada, çalışanların iş yerlerinde sıklıkla maruz kaldıkları rol belirsizliğinin sanal kaytarma davranışlarını nasıl etkilediği incelenmiştir. Analizler sonucunda, özel sektör çalışanlarının yaşadıkları rol belirsizliğinin sanal kaytarma davranışlarını artırdığı görülmüş, çalışmanın hipotezi desteklenmiştir. Sonuçlar, uluslararası literatürde bu iki değişkenin ilişkisini inceleyen sınırlı sayıdaki çalışmanın (Folkman ve Lazarus, 1988; Henle ve Blanchard, 2008; Sawitri ve Cahyadin, 2012; Sawitri, 2012) bulguları ile paralellik göstermektedir. Ulusal yazında ise rol belirsizliği ve sanal kaytarma ilişkini doğrudan konu alan herhangi bir çalışmaya rastlanılmamıştır. Bu bağlamda araştırma sonuçlarının özellikle ulusal düzeydeki sanal kaytarma literatürüne katkı sağlayacağı düşünülmektedir.

Araştırma sonuçlarına göre çalışanların rol belirsizliği algılarındaki azalma, sanal kaytarma davranışlarında anlamlı düzeyde düşüş sağlamaktadır. Bu çerçevede yöneticilerin, rol belirsizliğini asgari seviyeye indirmeleri önerilmektedir. Rol belirsizliğini azaltmak için kullanılabilecek yöntemler arasında; çalışanların iş yükünün dengeli ve adaletli bir biçimde paylaştırılması, beklentiler arasında uyumsuzluk veya zıtlığa mahal verilmeyecek şekilde görev ve sorumluluk dağıtımı yapılması ve çalışanlara bunlarla ilgili net bilgiler verilmesi, çalışanların hangi görevi nasıl yapacaklarına dair eksiksiz bilgilendirilmesi yer almaktadır (Doğan vd., 2016). Bununla birlikte yöneticiler, rol belirsizliğini artıran unsurlar için de önlem almalıdırlar. Çalışanın; yetkileri konusunda yeterince bilgi sahibi olmaması, üstleri tarafından net ve planlı olarak ulaşması istenen standartlar konusunda bilgilendirilmemesi, işiyle ilgili sorumluluklarını kavrayamamış olması, örgütün kendisinden neleri beklediğini net olarak bilmemesi, görev tanımının açıkça yapılmamış olması rol belirsizliğini arttıran etmenlerdir (Ceylan ve Ulutürk, 2006:49).

Her ne kadar rol belirsizliğini azaltmak, sanal kaytarma davranışlarında anlamlı düzeyde düşüşe sebep olsa da teknolojinin günümüzde gerek iş hayatında gerekse özel hayatta vazgeçilmez bir unsur haline gelmesi nedeniyle sanal kaytarma faaliyetleri giderek artış göstermektedir (Weatherbee, 2010:36). Nitekim 2000'li yılların başında gerçekleştirilen araştırmalar, çalışanların günlük 2,5 saatten haftalık 3 saate kadar sanal kaytarma yaptıklarını ortaya koymuştur (Greenfield ve Davis, 2002; Mills vd., 2001). Bu çalışmadaki sonuçlar da çalışanların yaklaşık \%40'ının sanal kaytarma faaliyetlerine günlük 1 saat veya daha fazla zaman harcadıklarını ortaya koymuştur. Bu sonuç, Demir vd. (2017)'nin araştırma sonuçları ile de benzerlik göstermektedir.

Sanal kaytarma, çalışanların mesai saatleri içerisinde esas görevlerini gerçekleştirmelerini engelleyerek ya da işlerin tamamlanma sürelerini uzatarak gerek zamanın gerekse diğer kurumsal kaynakların verimsiz kullanımına yol açmaktadır (Demir vd., 2017). Liberman vd. (2011) sanal kaytarmanın, hem örgüte hem de örgüt çalışanlarına zarar verdiğini, söz konusu zararların internet hatlarında meydana gelen yoğunluk, azalan verimlilik sonucu gerçekleşen milyarlarca dolarlık maddi kayıplar, şirket gizliliğinin ihlali, çalışanların işten çıkarılması ve hatta yasal yaptırımlar şeklinde olabileceğini vurgulamışlardır. Literatürde sanal kaytarmanın üretkenlik karşıtı bir eylem olduğunu 
savunan çalışmaların yanında, bazı durumlarda motivasyona ve verimliliğe katkı sağlayabileceğini öne süren çalışmalar da mevcuttur. Örneğin Blanchard ve Henle (2008)'e göre sanal kaytarma eylemlerinin iyi ve kötü olarak keskin bir ayrım ile sınıflandırılması doğru değildir. Öyle ki sanal kaytarma, çalışanların gelişimine katkı sağlayabilmekte (Ünal ve Tekdemir, 2015), çalışanların yaratıcılığını güçlendirme ve internet kullanımı konusunda verimliliği arttırmada da faydalı olabilmektedir (Garret ve Dangizer, 2008). Ancak sanal kaytarmanın etkisinin yalnızca çalışanların gelişimi ile sınırlı olmadığı ve bu tür davranışların gerek çalışan gerekse örgüt üzerinde olumsuz etkiler yaratacağı göz ardı edilmemeli, rol belirsizliği gibi unsurlar minimize edilirken işyerinde internet kullanımına yönelik politikalar belirlenmeli ve işverenler tarafından bu politikalara uyum düzeyi takip edilmelidir.

Literatürde sanal kaytarma davranışlarının işyeri bilgisayarları aracılığıyla gerçekleştiği varsayılmış ve sanal kaytarma bu şekilde kavramsallaştırılmış olsa da bu çalışma kapsamında örneklemin yarıdan fazlasının sanal kaytarma için yalnızca şahsi araçlarını kullandığı belirlenmiştir. Bu sonuçlar da Demir vd. (2007)'nin sonuçları ile uyumludur. Dolayısıyla çalışanların sanal kaytarma eylemlerini gerçekleştirmek için işyeri bilgisayarlarına bağımlı olmadıkları görülmektedir. İlerleyen dönemlerde yapılacak araştırmalarda, çalışanların hangi sanal kaytarma davranışlarını hangi cihazları kullanarak (işyeri bilgisayarı, cep telefonu ve tablet) gerçekleştirdikleri tespit edilebilir. Elde edilen veriler, örgütlerin sanal kaytarma davranışlarını kontrol altında tutmaları için kullanılabilir.

$\mathrm{Bu}$ araştırma, bazı kısıtlayıcı unsurlar barındırmaktadır. Araştırmanın rol belirsizliği ile sanal kaytarma davranışları arasındaki ilişkiye odaklanması çalışmanın özgün yönünü oluştursa da konunun daha önce az sayıdaki çalışmada tartışılmış olması, araştırma sonuçlarının kıyaslanmasına engel oluşturmaktadır. Ayrıca rol belirsizliği ve sanal kaytarma ilişkisi her ne kadar istatistiki olarak anlamlı olsa da rol belirsizliğinin sanal kaytarma üzerindeki etkisinin sınırlı düzeyde olduğu görülmüştür. $\mathrm{Bu}$ bağlamda, rol belirsizliği değişkeninin yanında rol çatışması ve aşırı rol yüklemesi gibi diğer rol stresörlerinin de oluşturulacak araştırma modelleri içerisinde yer alması önerilmektedir. Araştırma kapsamında sınırlı sayıda katılımcıdan veri toplanmıştır. Bu sebeple ulaşılan sonuçları genellemek mümkün değildir. İleride yapılacak olan çalışmalarda, örneklem büyüklüğü genişletilerek ve veri temin edilen bölgeler arttırılarak sonuçların genellenebilirliği arttırılabilir.

\section{KAYNAKÇA}

ACUNA, E. ve RODRIGUEZ, C. (2004). "The Treatment of Missing Values and Its Effect on Classifier Accuracy", (Ed.) BANKS, D., HOUSE, L., MCMORRIS, F.R., ARABIE, P. ve GAUL, W. Classification, Clustering, and Data Mining Applications, Springer, Berlin.

ANANDARAJAN, M., SIMMERS, C. ve IGBARIA, M. (2000). "An Exploratory Investigation of The Antecedents and Impact of Internet Usage: An Individual Perspective", Behaviour \& Information Technology, 19 (1), 69-85.

ASLAN, Ş. (2004). "Hastanelerde Örgütsel Çatışma: Teoriye Örnek Bir Uygulama”, Selçuk Üniversitesi Sosyal Bilimler Enstitüsü Dergisi, (11), 599-617.

BLANCHARD, A. L. ve HENLE, C. A. (2008). "Correlates of Different Forms of Cyberloafing: The Role of Norms and External Locus Of Control", Computers in Human Behavior, 24, 1067-1084.

CANDAN, H. ve İNCE, M. (2016). "Siber Kaytarma ve Örgütsel Bağl1lık Arasındaki İlişkinin İncelenmesine Yönelik Emniyet Çalışanları Üzerine Bir Araştırma”, Niğde Üniversitesi İktisadi ve İdari Bilimler Fakültesi Dergisi, 9(1), 229-235.

CEYLAN, A. ve ULUTÜRK, Y. H. (2006). "The Relationship Between Role Ambiguity, Role Conflict, Job Satisfaction, and Performance", Journal of Dogus University, 7(1), 48-58.

ÇAVUŞOĞLU, S., PALAMUTÇUOĞLU, B. T. ve PALAMUTÇUOĞLU, A. (2017). "İş Tatmininin Sanal Kaytarma Üzerindeki Etkisi”, Mehmet Akif Ersoy Üniversitesi Sosyal Bilimler Enstitüsü Dergisi, 9(19), 430-444. 
ÇivíLİDAĞ, A. (2017). "İş Yaşamında Sanal Kaytarmanın İş Stresi, İş Doyumu ile İlişkisi Üzerine Bir Araştırma", Akademik Bakış Uluslararası Hakemli Sosyal Bilimler Dergisi, (59), 355-373.

DEMIR, İ., ÜREK, D. ve UĞURLUOĞLU, Ö. (2017). "Sağlık Çalışanlarının Sanal Kaytarma Davranışlarının İşte Üretkenliklerine Etkisi”, AJIT-e: Online Academic Journal of Information Technology, 8(30), 291-303.

DIDDEN, R., SCHOLTE, R. H., KORZIILIUS, H., De MOOR, J. M., VERMEULEN, A., O'REILLY, M. ve LANCIONI, G. E. (2009). "Cyberbullying Among Students with An İntellectual and Developmental Disability in Special Education Settings", Developmental Neurorehabilitation, 12(3), 146-151.

DOĞAN, A., DEMIR, R. ve TÜRKMEN, E. (2016). "Rol Belirsizliğinin, Rol Çatışmasının ve Sosyal Desteğin Tükenmişliğe Etkisi: Devlet ve Vakıf Üniversitelerinde Çalışan Akademik Personelin Tükenmişlik Düzeylerinin Karşılaştırılması", Atatürk Üniversitesi İktisadi ve İdari Bilimler Dergisi, 30(1).

DURBIN, J. ve WATSON, G. S. (1951). "Testing for Serial Correlation in Least Squares Regression", II. Biometrika, 38 (1/2), 159-177.

ELDEM, M. O. (2017). Endüstri 4.0., TMMOB EMO Ankara Şubesi Haber Bülteni, 3, 2.

ERİGÜÇ, G. K. (1994). Hastanelerde Personelin İşle İlgili Tutumlanı Personel Devri Ankara İli Örneği, Yayımlanmamış Doktora Tezi, Hacettepe Üniversitesi Sağlık Bilimleri Enstitüsü, Ankara.

FOLKMAN, S. ve R. S. LAZARUS. (1988). "Coping As a Mediator of Emotion", Journal of Personality and Social Psychology, 54, 466-475.

GARRETT, R. K. ve DANZIGER, J. N. (2008). "Disaffection or Expected Outcomes: Understanding Personal Internet Use During Work", Journal of Computer-Mediated Communication, 13, 937 958.

GREENFIELD, D. N. ve DAVIS, R. A. (2002). "Lost in Cyberspace: The Web@ Work", CyberPsychology \& Behavior, 5(4), 347-353.

GÜNGÖR, M. (2016). Sanal Kaytarma ve Örgütsel Bağl1lık İlişkisi: Kamu ve Özel Sektör Üzerine bir Araştırma, Yüksek Lisans Tezi, Atatürk Üniversitesi Sosyal Bilimler Enstitüsü, Erzurum.

HAIR, J. F., BLACK, W. C., BABIN, B. J., ANDERSON, R. E. ve TATHAM, R. L. (2010). Multivariate Data Analysis, Pearson Prentice Hall, New Jersey.

HENLE, C. A. ve BLANCHARD, A. L. (2008). "The Interaction of Work Stressors and Organizational Sanctions on Cyberloafing", Journal of Managerial Issues, 20(3), 383-400.

KAHN, R. L., WOLFE, D. M., QUINN, R. P., SNOEK, J. D. ve ROSENTHAL, R. A. (1964). Organizational Stress: Studies in Role Conflict and Ambiguity, New York, NY, John Wiley \& Sons.

KORKUT, H., MUSTAN, T. ve YALÇINKAYA, M. (1999). "Araştırma Görevlilerinin Sorunları", Kuram ve Uygulamada Egitim Yönetimi Dergisi, 5(1), 19-36.

KOŞAR, S., SEZGIN, F. ve ASLAN, H. (2013). "Okul Müdürlerinin Resmî Görev Tanımlarının Dışında Olduğunu Düşündükleri İşlere İlişkin Görüşleri”, Gazi University Journal of Gazi Educational Faculty (GUJGEF), 33(1), 147-164.

LIBERMAN, B., SEIDMAN, G., MCKENNA, K. Y. ve BUFFARDİ, L. E. (2011). "Employee Job Attitudes and Organizational Characteristics As Predictors of Cyberloafing", Computers in Human Behavior, 27(6), 2192-2199.

LIM, V. K. G. (2002). "The IT Way of Loafing on The Job: Cyberloafing, Neutralizing and Organizational Justice”, Journal of Organizational Behavior, 23, 675-694. 
LIM, V. K. G., TEO, T. S. H., ve LOO, G. L. (2002). "How Do I Loaf Here? Let Me Count The Ways", Communications of the ACM, 45, 66-70.

LIM, V. K. G. ve TEO, T. S. H. (2005). "Prevalence, Perceived Seriousness, Justification and Regulation of Cyberloafing in Singapore: An Exploratory Study", Information and Management, 42, 1081-1093.

MAHATANANKOON, P. (2006). "Predicting Cyber-Production Deviance in The Workplace", International Journal of Internet and Enterprise Management, 4, 314-330.

MESSARRA, L. C., KARKOULIAN, S. ve MCCARTHY, R. (2011). "To Restrict or Not to Restrict Personal Internet Usage on The Job", Education, Business and Society: Contemporary Middle Eastern Issues, 4(4), 253-266.

MILLS, J. E., HU, B., BELDONA, S. ve CLAY, J. (2001). "Cyberslacking! A liability Issue For Wired Workplaces", Cornell Hotel and Restaurant Administration Quarterly, 42(5), 34-47.

MYSAMMY (2013). Cyberloafing Infographic: Personal internet use at work infographic. (E.T.: 03.05.2018). www.mysammy.com/cyberloafing-personal-Internet-use-at-work-infographic

NIAEI, M., PEIDAEI, M. M. ve NASIRIPOUR, A. A. (2014). "The Relation Between Staff Cyberloafing and Organizational Commitment in Organization of Environmental Protection", Kuwait Chapter of the Arabian Journal of Business and Management Review, 3(7), 59-71.

ÖĞÜT, E., ŞAHIN, M. ve DEMIRSEL, M. T. (2013). "The Relationship Between Perceived Organizational Justice and Cyberloafing: Evidence From a Public Hospital in Turkey", Mediterranean Journal of Social Sciences, 4, 226-233.

ÖRÜCÜ, E. ve YILDIZ, H. (2014). "İşyerinde Kişisel İnternet ve Teknoloji Kullanımı: Sanal Kaytarma”, Ege Akademik Bakış, 14(1), 99-114.

ÖZKALP, E., AYDIN, U. ve TEKELİ, S. (2012). "Sapkın Örgütsel Davranışlar ve Çalışma Yaşamında Yeni Bir Olgu: Sanal Kaytarma (Cyberloafing) ve İş İlişkilerine Etkileri”, Çimento İşveren, 26(2), 18-33.

POLATÇI, S. ve BOYRAZ, E. (2010). “Öğretmenlerin Öğrenilmiş Güçlülüklerinin Kaynak ve Sonuçlarına İlişkin Bir Model Önerisi”, Atatürk Üniversitesi İktisadi ve İdari Bilimler Dergisi, 24(4), 137-154.

RESTUBOG, S. L. D., GARCIA, P. R. J. M., TOLEDANO, L. S., AMARNANI, R. K., TOLENTINO, L. R., ve TANG, R. L. (2011). "Yielding to (Cyber)-Temptation: Exploring the Buffering Role of Self-Control in the Relationship Between Organizational Justice and Cyberloafing Behavior in the Workplace", Journal of Research in Personality, 45(2), 247-251.

RIZZO, J. R., House, R. J. ve LIRTZMAN, S. I. (1970). "Role Conflict and Ambiguity in Complex Organizations", Administrative Science Quarterly, 15(2),150-163.

SAWITRI, H. S. R. (2012). "Role of Internet Experience in Moderating Influence of Work Stressor on Cyberloafing", Procedia-Social and Behavioral Sciences, 57, 320-324.

SAWITRI, H. S. R. ve CAHYADIN, M. (2012). "The Moderation Effect of Commitment to Supervisor and Internet Expertise on Work Stressor and Employee Cyberloafing: The Study on Employee of Local Government of Surakarta", Journal of Indonesian Economy \& Business, 27(2), 271-284.

SHAMSUDIN, F. M., SUBRAMANIAM, C. ve ALSHUAIBI, A. S. (2012). "The Effect of HR Practices, Leadership Style on Cyberdeviance: The Mediating Role of Organizational Commitment", Journal of Marketing and Management, 3(1), 22-48.

SHARMA, S. K. ve GUPTA, J. N. (2004). 'Improving Workers' Productivity and Reducing Internet Abuse", The Journal of Computer Information Systems, 44, 74-78. 
UGRIN, J. C., PEARSON, J. M. ve ODOM, M. D. (2008). "Profiling Cyber-Slackers in The Workplace: Demographic, Cultural, and Workplace Factors", Journal of Internet Commerce, 6(3), 75-89.

URDAN, T. C. (2011). Statistics in Plain English, Routledge, New York.

ÜNAL, Ö. F. ve TEKDEMIR, S. (2015). "Sanal Kaytarma: Bir Kamu Kurumunda Ampirik Bir Araştırma”, Süleyman Demirel Üniversitesi İktisadi ve İdari Bilimler Fakültesi Dergisi, 20(2), 95-118.

VITAK J., CROUSE, J. ve LAROSE, R. (2011). "Personal Internet Use at Work: Understanding Cyberslacking", Computers in Behavior, 27(5), 1751-1759.

WEATHERBEE, T.G. (2010). "Counterproductive Use of Technology at Work: Information \& Communications Technologies and Cyberdeviance", Human Resource Management Review, 20(1), 35-44.

YILDIZ, H., YILDIZ, B. ve ATEŞ, H. (2014). "Sanal Kaytarma Davranışlarının Sergirilmesinde Örgütsel Adalet Algısının Rolü Var Mıdır?", 12. Uluslararası Bilgi, Ekonomi ve Yönetim Kongresi Bildirileri, 169-180.

YOUNG, K. S. (2001). "Managing Employee Internet Abuse: A Comprehensive Plan to Increase Your Productivity and Reduce Liability", Employee Internet Management, 1-37. 